\title{
TUBES BENDING BY TOD FROM ABRASION RESISTANCE CAST IRON
}

\author{
Alena BRUSILOVÁ, Alexander SCHREK, Pavol ŠVEC, Zuzana GÁBRIŠOVÁ, \\ Marcela POKUSOVÁ
}

\begin{abstract}
Faculty of Mechanical Engineering, Slovak University of Technology in Bratislava, Slovak Republic, EU, alena.brusilova@stuba.sk
\end{abstract}

https://doi.org/10.37904/metal.2019.814

\begin{abstract}
Due to the improvement of efficiency of power equipment (heat exchanger), it has been required to change the arrangement of exchanger tube bodies through the minimization of exchanger tubes bending radius. It was necessary to optimize process parameters and functional parts of forming tool to achieve the required parameters of tube bending. On the bending rail, which is one of the main parts of forming tool was used a newly developed type of cast iron with especially suitable characteristics minimizing a coefficient of friction during forming processes. In this paper we present the obtained results and material features in strain area of exc hanger tubes.
\end{abstract}

Keywords: Bending of tubes, bending radius, ovality, strain, abrasion resistance cast iron

\section{INTRODUCTION}

Rods, profiles and tubes bending is a specific technology which is characterised by a complicated combination of stress states [1,2] which are characterised by a spatial 3D bending in the formed material [3,4]. An extremely small bending radius of tubes results in the danger of the overstrength of the formed material in the outer bendig location [5], an increased wall thicknes in the inner bending location and the creation of the undesirable ovality [6]. All of these facts are, besides required geometry, also affected by a suitable construction and a material of forming tool. An enclosed area of the heat exchanger has limited size and its change hasn't been assumed. To improve its efficiency it was necessary to increase the size of a heat transfer area by increasing the number of exchanger tube bodies. Obtaining this increase was possible by minimization of bending radius of anguineform tube exchanger system. Required tube bending radius was achieved by choosing the suitable tube material and adjusting the forming tool with the change of the material of the bending rail decreasing the coefficient of friction during bending process.

\section{PROBLEM CHARACTERISTICS}

The heat exchanger is a compound of a casing and a system of anguine arranged tubes according to Figure 1. To enlarge the surface of the water heater, the anguine seamless tubes with changed bending radius have been designed in such a way that it has been possible to give more pieces of the anguine tubes into the original heater area. The bending radius up to the neutral axis of the anguine tubes has been reduced to $R=$ $40 \mathrm{~mm}$. The designed thick-wall seamless tubes of sizes $38 \mathrm{~mm} \times 5 \mathrm{~mm}$ are made of material 1.0345 (P235GH) with a chemical composition according to Table 1.

Table 1 Chemical composition of $\mathrm{P} 235 \mathrm{GH}$ steel

\begin{tabular}{|c|c|c|c|c|c|c|c|c|c|}
\hline Chemical component & $\mathrm{C}$ & $\mathrm{Si}$ & $\mathrm{Mn}$ & $\mathrm{Ti}$ & $\mathrm{V}$ & $\mathrm{Mo}$ & $\mathrm{Cu}$ & $\mathrm{Cr}$ & $\mathrm{Ni}$ \\
\hline (wt. \%) & 0.016 & 0.350 & 1.200 & 0.030 & 0.020 & 0.080 & 0.300 & 0.300 & 0.200 \\
\hline
\end{tabular}

It is a carbon plain heat resistant steel suitable for pressure vessels and seamless tubes stressed to compression with yield strength $R e=235 \mathrm{MPa}$, tensile strength $R m=500 \mathrm{MPa}$ and ductility $A=25 \%$, suitable 
for work at increased temperature. It is characterized by a good weldability. It is used especially for production of boilers, pressure vessels and tubes used for transport of hot liquid. It is able to accept a long-time heat load up to $450^{\circ} \mathrm{C}$. It has a good cold and warm formability.

\subsection{Bending of the anguine tube system}

The tube bending has been performed by bending machine RLS-63 with special tools (Figure 2) made for specific bending radius and tube diameter.

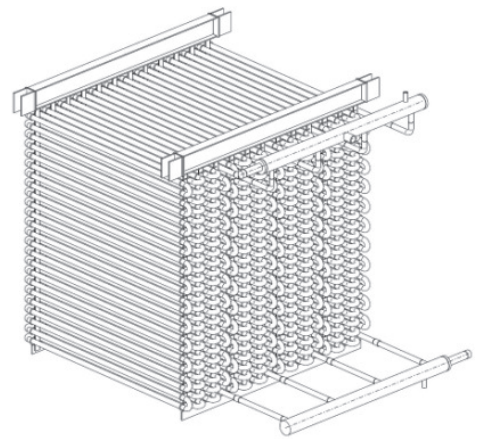

Figure 1 The scheme of re-designed heat exchanger internal arrangement

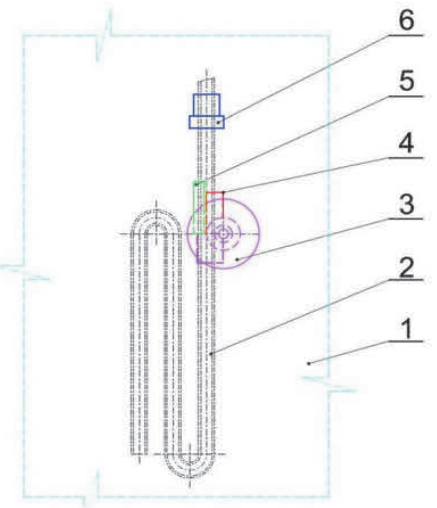

Figure 2 The bending scheme on RL-63

\section{Bending disc}

It is the most important segment of special tools. For each tube and each bending radius, we need a special bending disc with required dimensions. It is made of Ni-Cr-Mo-V tool steel 1.2714 (55NiCrMoV7). It consists of two parts and it is prepared for usage by connecting these parts together. The construction of the disc allows tube bending with angle over $180^{\circ}$ (Figure 3 ).
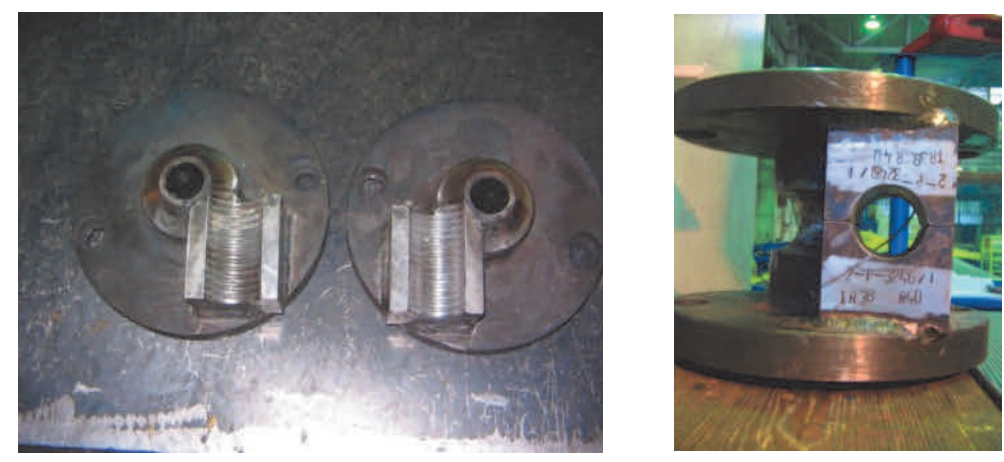

Figure 3 The decomposed and composed bending disc

\section{Bending rail}

The bending rail (Figure 4) is used for tube bending. The functional part of bending rail holds and forms around bending disc the outer part of bend tube during bending process. To improve friction it was made of a new type of cast iron $\mathrm{Cr} 21 \mathrm{Ni5}$ with $21 \%$ of chromium. It is especially suitable to adhesive and abrasive wear in various types of forming tools [7]. The chemical composition of Cr21Ni5 cast iron is adduced on Table 2.

Table 2 Chemical composition of cast iron $\mathrm{Cr} 21 \mathrm{Ni} 5$

\begin{tabular}{|c|c|c|c|c|c|c|}
\hline Element & $\mathrm{C}$ & $\mathrm{Si}$ & $\mathrm{Mn}$ & $\mathrm{Cr}$ & $\mathrm{Mo}$ & $\mathrm{Ni}$ \\
\hline wt. \% & 3.38 & 0.45 & 0.9 & 20.62 & 1.47 & 5.42 \\
\hline
\end{tabular}


The average hardness of cast iron after casting was $545 \mathrm{HV} 30$. After austenitization at $900{ }^{\circ} \mathrm{C}$ for 1 hour and tempering at $450^{\circ} \mathrm{C}$ for 2 hours, the hardness has reached average value of $570 \mathrm{HV} 30$ and increase in value $4.58 \%$. After tempering at $600{ }^{\circ} \mathrm{C}$ for 2 hours, the hardness has reached average value of $599 \mathrm{HV} 30$ and increase in value $9.9 \%$ in comparison to the state after casting [8].

\section{Clamping jaws}

The clamping jaws (Figure 5) press the tube into a bend. They have been made of tool steel 1.2080 (X210Cr12).

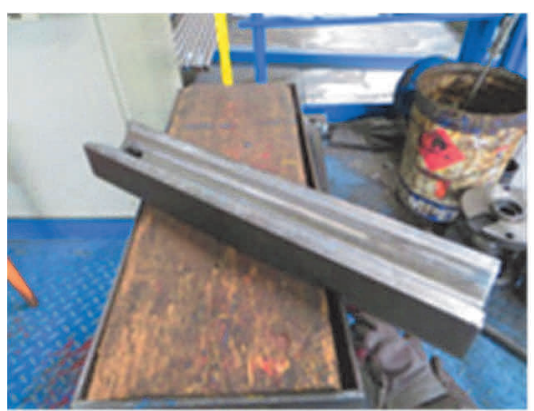

Figure 4 Bending rail

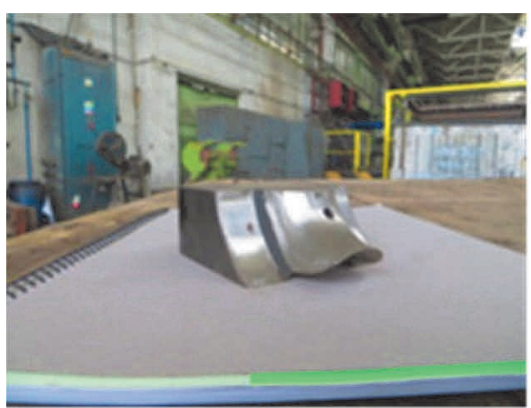

Figure 5 Clamping jaws

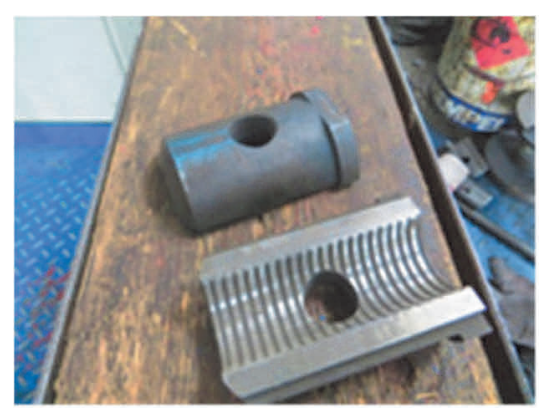

Figure 6 Compensator of wrinkles

\section{Equalizer of wrinkles}

The equlizer of wrinkles (Figure 6) creates a smooth bend and in the process of bending prevents tube from unwanted wrinkling.

\subsection{Tubes bending progress}

The tube bending has been carried out on the bending machine RLS-63 by coiling on a forming segment bending disc without a mandrel. Choosing the suitable form and material of the pressure rail and the bending disc we achieved the correct shape of cross-section with low ovality values. The straight seamless tubes were welded on the required length, before the bending process. After welding, the tubes were clensed from impurities, rust and sludge. The feeding unit transported the tubes into the measuring system. The tubes were received between rollers and forwarded in the required length into the bending unit. The tubes were clamped in the bending drum and rotated simultaneously with the drum. The bending parameters have been adjusted through the bending machine control system:

- $\quad$ a bending rail pressure 80 bar (8 MPa)

- $\quad$ a system pressure generating bending force 85 bar (8.5 MPa)

- a tube clamps pressure 130 bar (13 MPa)

The bending process has been carried out without any difficulties, there was no need to fill the tubes with fillers to avoid flattening. After bending, there were no visual defects on the surface and cracks on the tubes.

\subsection{Tube properties analysis in strain zone}

\section{Re-designed tubes deformation and ovality}

The bending angle was $180^{\circ}$, the tube was divided into 6 segments /sections in $30^{\circ}$ of bending, i.e. $30^{\circ}, 60^{\circ}$, $90^{\circ}, 120^{\circ}, 150^{\circ}$ and $180^{\circ}$. For visual comparison, the section in $0^{\circ}$ is illustrated in Figure 7.

The ovality in each individual section was calculated on the basis of measured values of maximal and minimal diameter (Table 3). The highest value was found in the section $180^{\circ}-8.277 \%$ that is less than the standard EN 12952 specified value $12 \%$ for tube bending. 
Table 3 The tube diameters in strain zone

\begin{tabular}{|c|c|c|c|c|c|c|}
\hline Angle section $\boldsymbol{\alpha}$ & $30^{\circ}$ & $60^{\circ}$ & $90^{\circ}$ & $120^{\circ}$ & $150^{\circ}$ & $180^{\circ}$ \\
\hline Maximal diameter tube domax $(\mathbf{m m})$ & 38.1 & 38.0 & 37.9 & 37.8 & 38.5 & 39.0 \\
\hline Minimal diameter tube $\boldsymbol{d}_{\text {omin }}(\mathbf{m m})$ & 36.9 & 37.0 & 36.5 & 35.9 & 36.2 & 35.9 \\
\hline
\end{tabular}

\section{Tube wall thickness in strain zone}

The tube wall thickness has been measured on the longitudal section in $15^{\circ}$ of bending (Figure 8). The more noticable tube wall thickening already occured during the first bending stage ( $15^{\circ}$ of section bending). This thickness increased during the following stages of bending up to the highest values which were achieved in $150^{\circ}-180^{\circ}$ angle sections. The thickness growth continued even after bending was finished. The tube wall thinning on the outside of the bend was approximately the same during all stages of bending. The lowest value of wall thickness was measured in $90^{\circ}$ angle section.

\section{Change hardness of material during bending}

The changes of mechanical features of material in strain zone have been determined by Vickers hardness test HV10. On the single sections of tube, 3 incisions have been applied in a neutral zone, in a zone of wall tube thickening and a zone of tube wall thinning (Figure 9). The measured values comparison is in Figure 10. The hardness measured by Vickers test and their calculation of strength are in Table 4. The Figure 11 shows comparison of hardness in the strain zone.

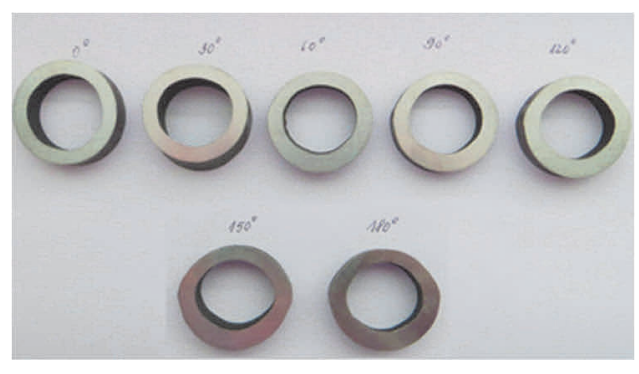

Figure 7 The bend cross-sections of tube

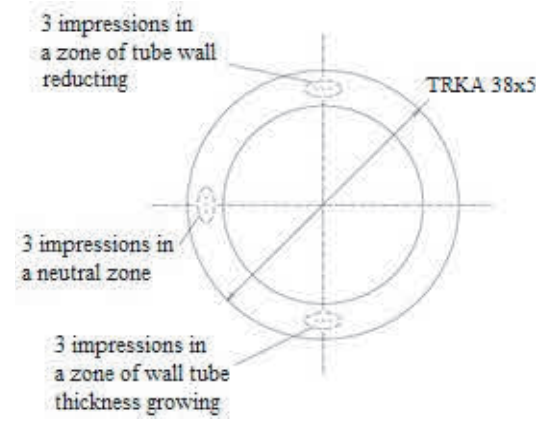

Figure 10 The measuring points of hardness on a tube cross-sections

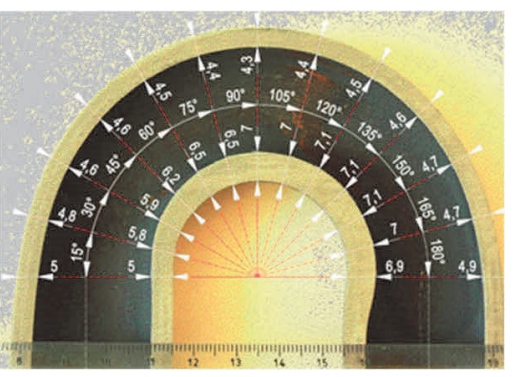

Figure 8 The bend longitudinal section of tube

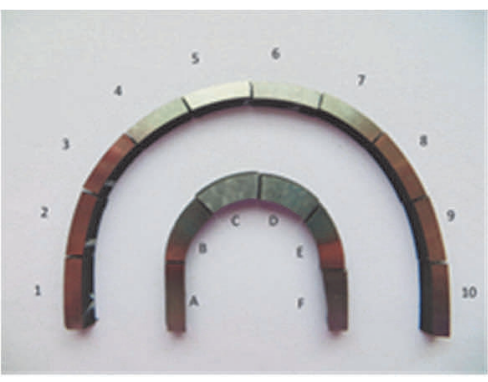

Figure 9 The samples for metallographic analysis

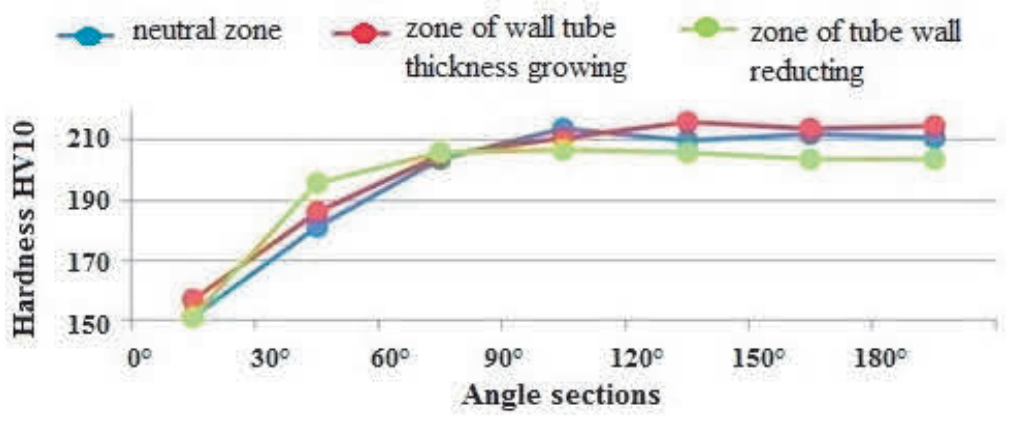

Figure 11 The hardness comparison in a strain zone

From the graph and the table it is obvious that the initial hardness and strength of material in range 150-160 HV (strength 477 - $510 \mathrm{MPa}$ ) has increased by the influence of deformation strain hardening in strain zone of the bend up to $216 \mathrm{HV}$ resp. the strength up to $694 \mathrm{MPa}$ what represented a hardness and strength increase about $43 \%$. The value differences in a neutral zone, in a zone of thickness growth and a zone of thinning were minimal. The highest hardness values were measured in the inner side of the bend as a consequence of the large material accumulation, thickening of the tube wall and deformation strain hardening in the bend. 
Table 4 The hardness and strength of tube material in strain zone

\begin{tabular}{|c|c|c|c|c|c|c|c|}
\hline \multirow{2}{*}{ Neutral zone } & \multicolumn{7}{|c|}{ Angle section } \\
\cline { 2 - 9 } & $0^{\circ}$ & $30^{\circ}$ & $60^{\circ}$ & $90^{\circ}$ & $120^{\circ}$ & $150^{\circ}$ & $180^{\circ}$ \\
\hline Hardness HV10 & 151 & 181 & 204 & 214 & 210 & 212 & 211 \\
\hline Strength (MPa) & 483 & 579 & 656 & 686 & 676 & 682 & 678 \\
\hline \multirow{8}{*}{ Zone of wall tube thickness growing } & \multicolumn{7}{|c|}{ Angle section } \\
\cline { 2 - 9 } & $0^{\circ}$ & $30^{\circ}$ & $60^{\circ}$ & $90^{\circ}$ & $120^{\circ}$ & $150^{\circ}$ & $180^{\circ}$ \\
\hline Hardness HV10 & 157 & 186 & 205 & 211 & 216 & 214 & 215 \\
\hline Strength (MPa) & 500 & 598 & 660 & 678 & 694 & 686 & 690 \\
\hline Zone of tube wall reducing & \multicolumn{7}{|c|}{ Angle section } \\
\hline Hardness HV10 & $0^{\circ}$ & $30^{\circ}$ & $60^{\circ}$ & $90^{\circ}$ & $120^{\circ}$ & $150^{\circ}$ & $180^{\circ}$ \\
\hline Strength (MPa) & 151 & 196 & 206 & 207 & 206 & 204 & 204 \\
\hline
\end{tabular}

\section{Microscopic analysis}

The sample 5 was selected for analysis of the shape of the grains in the plastic deformation zone of the outer tube circumference where the reduction in wall thickness occured. The microstructures of outer and inner bending radius side (Figure 12) are characterized by diffent grain shape of the outer tube circumference. On the outer side texture is identifiable in the direction of bending.
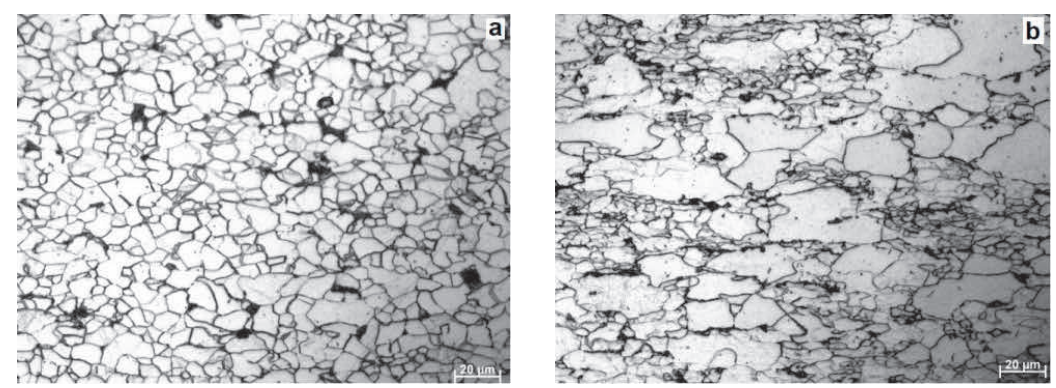

Figure 12 Microstructure of the sample 5 a) inner bending radius side, b) outer bending radius side
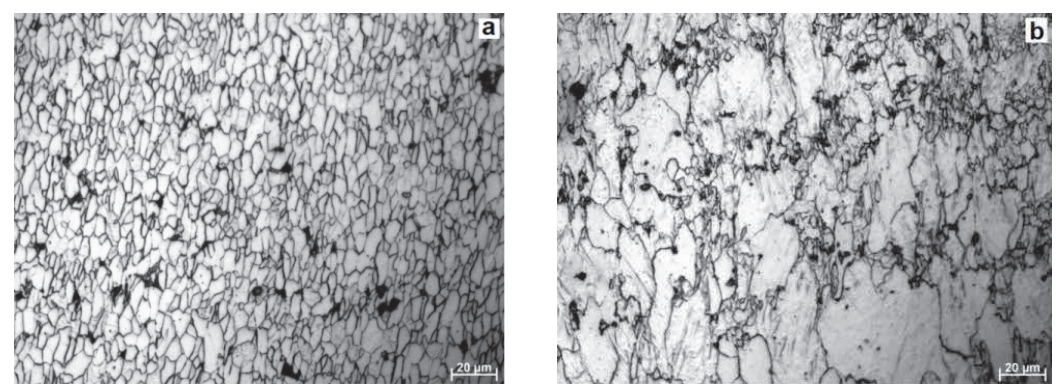

Figure 13 Microstructure of the sample $\mathrm{C}$ a) inner bending radius side, b) outer bending radius side

The sample $\mathrm{C}$ was selected for material analysis in the plastic deformation zone in the inner tube circumference where the growth in the wall thickness occured.Pressure stress effect and a texture created by grains with bigger dimension oriented in the perpendicular direction to bending were observed in the sample $\mathrm{C}$ obtained in $80^{\circ}$ angle section (Figure 13). The flattened grains are visible on the inner and also outer bending side of 
the inner tube circumference. Neither macro nor microcracks nor other defects were observed in the bending zone.

\section{CONCLUSION}

The aim of this paper was to achieve a minimal bending radius of heat exchanger tube body and efficiency improvement of power generating unit. In order to achieve this aim a new technological equipment of the bending machine was necessary. New type of material - abrasive cast iron $\mathrm{Cr} 21 \mathrm{Ni5}$ minimazing friction coefficient during bending process was used in one of the key parts - the bending rail. The tube bending of the anguine system has been performed on the bending machine RLS-63 by coiling on a bending disc without a mandrel. The usage of this equipment and machine avoided creation of undesirable defects and unacceptable tube ovality. No surface defects and cracks were detected on the tubes after bending. The tube deformation analysis in strain zone was carried out according to the standard EN 12952 and the maximal and minimal diameter was measured. The calculated ovality values of individual sections of tube were below standard value. The analysis of the tube wall thickness changes on outside and inside of the bend showed a linear wall thickness reducing to $90^{\circ}$ angle section along the outer circumference of tube. After this, the wall thickness started increasing. When the bending was finished it reached the initial value. The wall thickness increased by influence of compression stress acting on the inside of the bend. The thickness growth occured directly at the beginning of the bending process and it was constantly increasing during the bending process as a consequence of large material accumulation and conservation of volume. The thickness growth continued even shortly after the bending was finished. The analysis of the material hardness confirmed increasing of the hardness and strength values by about $43 \%$ as the influence of deformation strain hardening. The realised tubes bending of heat exchanger fulfil the standard determined values of acceptable ovality and show no visible defects and therefore the heat exchangers production has successfully been realized. Time will show the life expectancy of these machines.

\section{ACKNOWLEDGEMENTS}

This work was supported by the Slovak Research and Development Agency under the contract No. APVV-16-0485 and University Science Park STU Bratislava "ITMS code 26240220084". We would like to thank the Slovak grant agency VEGA for the financial support of the project VEGA 1/0405/19.

\section{REFERENCES}

[1] SAURABH, D., SAMUEL, H.H., JUN, S. and WILLIAM, H.V. Yield prediction for seamless tubing processes: computational intelligence approach. Int J Adv Manuf Technol.2008. vol. 37, pp. 314-322.

[2] JAMALI, S.S., FARAJI, G. and ABRINIA, K. Hydrostatic radial forward tube extrusion as a new plastic deformation method for producing seamless tubes. Int J Advance Manufacturing Technology. 2017. vol. 88, pp. 291-301.

[3] ATANASIU, N. Optimierung der technologischen Parameter beim Ziehen von Rohren auf fliegendem Dorn. Metalurgia. 1980. no. 8, pp. 45-52.

[4] MÄKELT, H. Tiefziehen und Abstrecken, Pressenhandbuchder Fa. Kießerling. Solingen. 1979.

[5] KU, T.-W., CHA, J.-H., KIM, Y.-B., KWAK, O.-G., KIM, W.-S. and KANG, B.-S. A study on process parameters for cold U-bending of SUS304L heat transfer tube using rotary draw bending. Journal of Mechanical Science and Technology. 2013. vol. 27, no. 10, pp. 3053-3061.

[6] GOLUBČIK, R.M. and POLUCHIN, P.I. Issledovanie processov proizvodstva trub. Metallurgia. 1970.

[7] MURGAŠ, M. and POKUSOVÁ, M. High-chromium cast iron with higher ductility. Archives of foundry engineering. 2006. vol. 6, no. 18, pp. 171-176.

[8] POKUSOVÁ, M., BRUSILOVÁ, A., ŠOOŠ, L'. and BERTA, I. Abrasion wear behavior of high-chromium cast iron. Archives of foundry engineering. 2016. vol. 16, pp. 69-74. 